ISSN 0258-7122

Bangladesh J. Agril. Res. 38(2): 335-341, June 2013

\title{
GENETIC DIVERSITY IN EXOTIC MAIZE (Zea mays L.) HYBRIDS
}

\author{
M. A. ZAMAN $^{1}$ AND M. A. ALAM ${ }^{2}$
}

\begin{abstract}
An experiment in alpha lattice design with three replication including 39 exotic maize hybrids was conducted at the Research farm of Regional Agricultural Research Station, BARI, Ishuardi, Pabna during Rabi season 2010-11 for analysis the genetic divergence in exotic maize hybrids. The genotypes were grouped in to seven clusters. Cluster VI comprised the maximum genotypes (13) indicating overall genetic similarity among them. The minimum genotype (1) was contained in the cluster III and V. The highest inter-cluster distance was observed between cluster V and III followed by cluster I and III and cluster III and VII suggesting wide diversity between them and the genotypes in these cluster could be used in hybridization program for obtaining a wide spectrum of variation among the segregates. The highest intra-cluster distance was observed in cluster VII and the cluster III and $\mathrm{V}$ were contained only one genotype and hence, their intra cluster distance was zero. The mean values of cluster IV recorded the highest yield per hectare (11.60 ton/ha) with medium plant height, days to maturity, days to $50 \%$ tasseling, silking and shelling percentage. Selection on the basis of plant aspect and ear aspect the genotypes of cluster III ranked first but plant height was high with medium seed size, medium yield, medium shelling percentage and also in late in case of maturity. The mean values of cluster $\mathrm{V}$ shown overall medium in case of yield and all yield contributing characters. Qualitative characters contribute maximum towards genetic divergence. Therefore, the genotypes from cluster III, V and VI could be utilized as source materials for getting desirable new recombinants with early maturity and higher yield.
\end{abstract}

Keywords: Genetic divergence, cluster analysis, $\mathrm{D}^{2}$ analysis, maize (Zea mays L.).

\section{Introduction}

Maize (Zea mays L.) is the most widely grown also leading cereal in the world due to its productivity. It is the third most important cereal after rice and wheat in Bangladesh. The cultivated area and production of maize is increasing day by day due to it's yield potentiality. High yield potentiality and it's multipurpose use as food can be reduced the wheat production area and maize imports. Maize is also the most demandable cereal food of the poultry industry in our country.

${ }^{1}$ Scientific Officer, RWRC, Bangladesh Agricultural Research Institute (BARI), ${ }^{2}$ Scientific Officer, RARS, BARI, Ishuardi, Pabna, Bangladesh. 
Assessment on genetic diversity among the genotypes is important for planning an effective breeding programme as the genetically diverged genotypes are important for adaptation of high heterotic hybrids under different ecological zones in the country. It has become possible to quantify magnitude of genetic diversity among germplasm with the help of advanced biometrical method, such as multivariate analysis (Rao, 1952) based on Mahalanobis' (1936) $\mathrm{D}^{2}$ statistics. A number of advanced maize hybrids from CIMMYT need assessment of variation among them for evaluation of their potentiality. The multivariate approaches of analysis of variation among the lines were done under the present investigation.

\section{Materials and Method}

The experiment was conducted at the RARS, Ishurdi, Pabna during rabi 2010-11. Thirty seven exotic hybrids along with two local check as BARI Hybrid Maize 5 and 9 were included in the study. Seeds of the thirty nine hybrids were sown on 22 December 2010 in an alpha lattice design with three replications. Unit plot size was $5 \mathrm{~m} \times 1.5 \mathrm{~m}$ maintaining a spacing of $70 \mathrm{~cm} \times 20 \mathrm{~cm}$. One plant was kept per hill after thinning. Fertilizers were applied at the rate of 250, 120, 120, 40, and $5 \mathrm{~kg} / \mathrm{ha}$ of $\mathrm{N}, \mathrm{P}_{2} \mathrm{O}_{5}, \mathrm{~K}_{2} \mathrm{O}, \mathrm{S}$, and $\mathrm{Zn}$, respectively. The other intercultural operations were done to raise the crop uniformly. Data on plant and ear height, thousand grain weight, shelling percentage and field weight were recorded on 10 randomly selected competitive plants for each treatment in each replication except for days to $50 \%$ tasseling, days to $50 \%$ silking and maturity, plant and ear aspect, thousand grain weight and yield per hectare, which were recorded on the plot basis. Two qualitative data on plant and ear aspect were calculated to observe the over all performance of Plant and Ear of the respective hybrid under field condition followed by 1-5 scale, 1 for best 2 for good 3 for moderately good 4 for bad and 5 for very bed. The mean of the 10 plants were subjected to statistical analysis. Data were subjected to analysis of Mahalanobis' $\mathrm{D}^{2}$-statistics. Intra-cluster and inter-cluster distance, cluster mean and contribution of each trait to the divergence were estimated as suggested by Singh, R. K. and Chaudhary, B. D. (1985).

\section{Results and Discussion}

The analysis of variance revealed highly significant differences among the hybrids for all the eleven characters indicating the existence of genetic variability among the experimental genotypes. The thirty nine hybrids were 
grouped into seven clusters using the non-hierarchical clustering method by Genstat Version 3 software programme in such a way that the genotypes within the cluster had smaller $\mathrm{D}^{2}$ values among themselves than those belonging to different clusters (Table 1). Pattern of distribution of genotypes among various clusters reflected the considerable genetic variability present in the hybrids under study. The maximum number of hybrids (13) was comprised into cluster VI indicating overall genetic similarity among them, whereas cluster IV and VII was consisted of 8 and 6 genotypes, respectively. Five hybrids were included in each of cluster I and II. The minimum hybrid (1) comprised into cluster III and V.

Table 1. Distribution of exotic maize hybrids in different clusters distribution.

\begin{tabular}{l|l|l}
\hline \multicolumn{1}{c}{ No. of clusters } & No. of hybrids & \multicolumn{1}{c}{ Serial no. of hybrids } \\
\hline I & 5 & $6,15,24,34$ and 39 \\
II & 5 & $11,21,28,33$ and 36 \\
III & 1 & 1 \\
IV & 8 & $4,12,19,20,22,23,25$ and 30 \\
V & 1 & 2 \\
VI & 13 & $3,5,7,13,14,16,17,26,27,29,32,35$ and \\
& & 38 \\
VII & 6 & $8,9,10,18,31$ and 37 \\
\hline
\end{tabular}

The intra and inter cluster distance $\left(\mathrm{D}^{2}\right)$ values worked out from divergence analysis are presented in Table 2. The inter-cluster distances in all cases were larger than the intra-cluster distance which indicated that wider diversity is present among the genotypes of distant group. The genotypes included within a cluster had less diversity among themselves. The highest inter-cluster distance of 22.564 was observed between cluster V and III followed by 20.422 between cluster I and III and 19.947 between cluster III and VII suggesting wide diversity between them and the hybrids in these cluster could be used as parents for inbred line development which can be used for new hybrids. In this context, hybrids from cluster III, V and VII should be selected as parents for development of new inbreds to be used in new hybrid program of maize. These finding were supported by Datta, and Mukherjee (2009) and Singh et al. (2005). A two dimensional scattered diagram was constructed using principal component score I (PCA score-I) as "Y" axis and principal component II (PCA score-II) "X" axis, reflection the relative position (Fig. 1). As per scattered diagram, the genotypes were apparently distributed into seven clusters; it was also revealed that the genotypes of cluster V were more diverse from the genotypes of cluster VII and 
Table 2. Average intra (Bold) and inter cluster distance $\left(\mathrm{D}^{2}\right)$ for 39 exotic maize hybrids.

\begin{tabular}{|c|c|c|c|c|c|c|c|}
\hline \multirow{2}{*}{ Cluster } & \multicolumn{7}{|c|}{ Cluster } \\
\hline & I & II & III & IV & $\mathrm{V}$ & VI & VII \\
\hline I & 0.3185 & 7.314 & 20.422 & 5.407 & 12.363 & 3.968 & 6.398 \\
\hline II & & 0.2682 & 17.831 & 7.091 & 13.614 & 4.203 & 5.049 \\
\hline III & & & 0.0000 & 17.027 & 22.564 & 17.742 & 19.947 \\
\hline IV & & & & 0.3625 & 9.980 & 3.861 & 8.541 \\
\hline V & & & & & 0.0000 & 11.686 & 16.054 \\
\hline VI & & & & & & 0.3147 & 5.236 \\
\hline VII & & & & & & & 0.3764 \\
\hline
\end{tabular}

III. The graphical scenario also confirmed the result presented in the Table 1 and 2. The lowest inter-cluster distance of 3.861 existed between cluster IV and VI followed by 3.968 between I and VI and 4.203 between cluster II and VI indicating a close relationship between the same grouped. The highest intracluster distance was observed 0.3764 in cluster VII and the clusters III and V

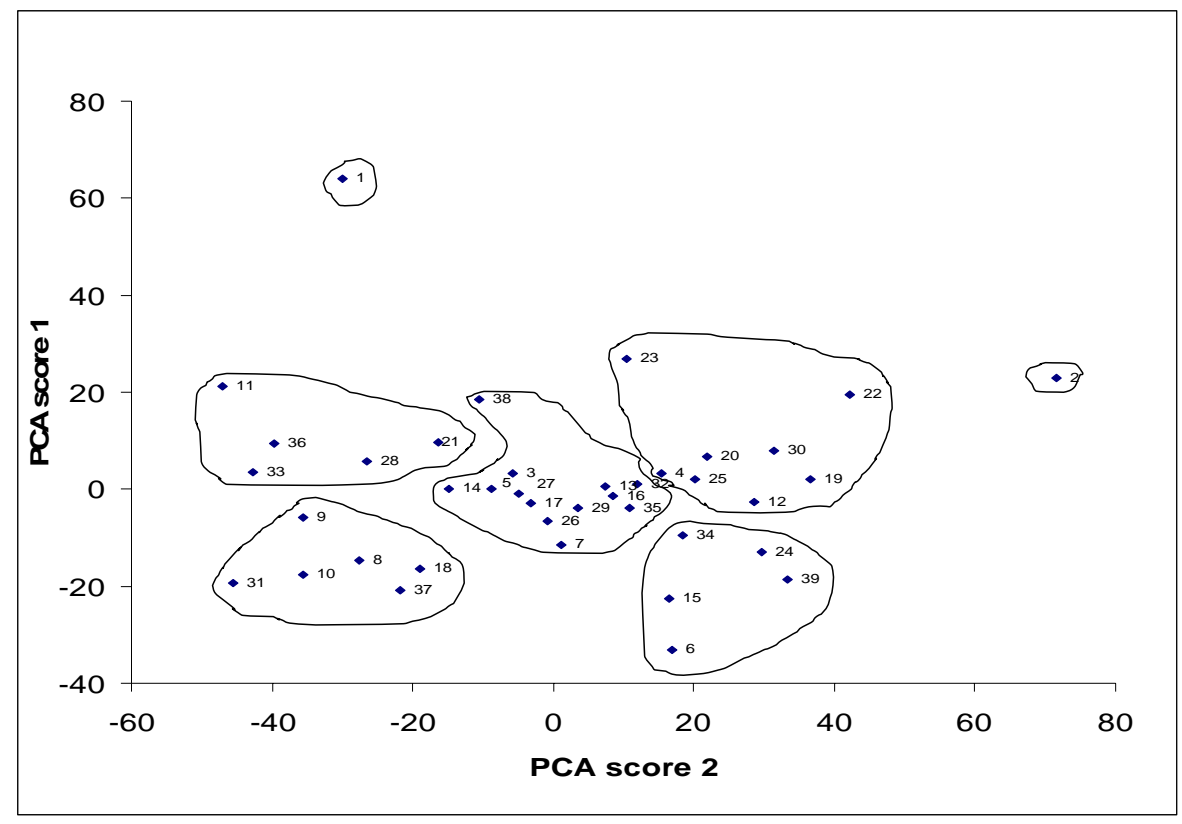

Figure 1. Distribution of 39 exotic maize genotypes in a two dimensional scatter diagram based on PCA scores superimposed with clusters. 
contained only one genotype and hence, their intra cluster distance was zero (0.000) (Table 3). The mean values of cluster VII ranked first for early days to maturity (149 days), days to 50\% silking (98 days), and tasseling (98 days), medium ear height, medium seed size, and medium yield per hectare (10.40 ton/ha) (Table 3). The mean values of cluster IV recorded the highest yield per hectare (11.60 t/ha) with medium plant height, days to maturity (236 days), days to 50\% tasseling (99 days), silking (100 days) and shelling percentage (77.20\%). Selection on the basis of plant aspect and ear aspect, the genotypes of cluster III ranked first but plant height was high with medium seed size, medium yield (11.10 t/ha), medium shelling percentage and also late in case of maturity (Table $3)$. The mean values of cluster V showed overall medium in case of yield and all yield contributing characters. Therefore, the hybrids from cluster III, V, and VI could be utilized as source materials for getting desirable transgressive segregants and having maximum yield along with short duration. Singh and Chauwdhary (2001) also reported wide range of variation for grain yield and its components in maize.

Table 3. Clusters mean for different quantitative and qualitative characters of $\mathbf{3 9}$ exotic maize hybrids.

\begin{tabular}{l|c|c|c|c|c|c|c}
\hline \multirow{2}{*}{ Characters } & \multicolumn{7}{c}{ Clusters mean values } \\
\cline { 2 - 8 } & I & II & III & IV & V & VI & VII \\
\hline Days to tasseling & 98.90 & 99.10 & 101.30 & 99.40 & 101.00 & 99.60 & 98.50 \\
Days to silking & 99.50 & 99.60 & 102.70 & 99.80 & 102.30 & 99.80 & 98.50 \\
Days to maturity & 150.20 & 151.20 & 152.70 & 150.10 & 150.30 & 150.80 & 149.20 \\
Plant height & 214.40 & 235.90 & 304.80 & 235.70 & 230.20 & 229.00 & 219.10 \\
Ear height & 109.20 & 131.30 & 119.50 & 127.10 & 164.90 & 121.10 & 109.20 \\
Plant aspect & 2.60 & 1.90 & 1.80 & 2.20 & 1.70 & 2.30 & 2.20 \\
Ear aspect & 2.10 & 1.80 & 1.70 & 1.90 & 2.20 & 2.20 & 2.20 \\
Field weight & 9.70 & 11.10 & 10.90 & 11.00 & 10.10 & 10.50 & 10.30 \\
1000-grain weight & 345.90 & 404.90 & 393.50 & 343.50 & 302.30 & 369.80 & 399.90 \\
Shelling percentage & 78.90 & 79.00 & 71.00 & 77.20 & 74.30 & 77.40 & 76.50 \\
Yield(t/ha) & 10.20 & 11.50 & 11.10 & 11.60 & 10.10 & 10.90 & 10.40 \\
\hline
\end{tabular}


Contributions of the characters towards divergence are presented in Table 4. The canonical analysis revealed that values in both vectors (Vector I and II) for plant aspect and ear aspect were positive, values in one vectors (latent vector 2) for days to $50 \%$ tasseling, silking, days to maturity, plant height and ear height were positive. Such results indicated that qualitative characters (plant aspect and ear aspect) contributed maximum towards total divergence of the hybrids and it was also suggested that attention should be given for these five quantitative characters and two qualitative characters (plant height and ear height) for yield improvement of maize. Similar finding was recorded by Marker, and Krupakar (2009).

Table 4. Relative contributions of the nine characters of 39 maize hybrids to the total divergence.

\begin{tabular}{lcc}
\hline Characters & Latent vectors 1 & Latent vectors 2 \\
\hline Days to tasseling & -0.3459 & 0.4410 \\
Days to silking & -0.3191 & 0.4733 \\
Days to maturity & -0.3574 & 0.0110 \\
Plant height & -0.3463 & 0.1022 \\
Ear height & -0.2554 & 0.0202 \\
Plant aspect & 0.1450 & 0.1798 \\
Ear aspect & 0.3031 & 0.2618 \\
Field weight & -0.4189 & -0.3063 \\
Thousand grain wt & 0.0002 & -0.3036 \\
Shelling percentage & 0.0177 & -0.4462 \\
Yield (kg/ha) & -0.4207 & -0.2907 \\
\hline
\end{tabular}

\section{References}

Datta, D. and B. K. Mukherjee. 2004. Genetic divergence among maize (Zea mays L.) inbreds and restricting traits for group constellation. Indian Journal of Genetics 64(3): 201-207.

Mahalanobis, P. C. 1936. On the generalized tistance in statistics. Nat. Inst. Sci. Ind. B. Z.: 49-55.

Rao, C. R. 1952. Advanced Statistical Method in Biometric Research. Ednl. John Wiley and Sons, New York. 
Singh P., Sain Das, V. K. Dwivedi, Y. Kumar and O. Sangwan. 2005. Genetic divergence studies in maize (Zea mays L.). Annals of Agric. Bio. Res. 10(1): 43-56.

Singh, R. K. and B. D. Chaudhary. 1985. Biometrical methods in quantitative genetic analysis. Kalyani Publ., New Delhi.

Marker, S. and A. Krupakar. 2009. Genetic diversity in exotic maize germplasm (Zea mays L.). ARPN Journal of Agricultural and Biological Science 4(4): 44-47.

Singh P. K.and Chaudhary L. B. 2001. Genetic divergence in maize (Zea mays L.). Journal of Research, Birsa Agricultural University 20(4): 317-320. 